\title{
Toque De Recolher E Lockdown: A Mutação Inconstitucional Promovida Pelas Autoridades Locais No Combate À Covid-19 No Brasil
}

\begin{abstract}
Henrique Breda Cavalcanti *
Universidade Federal da Bahia, Programa de Pós-Graduação em Direito, Salvador-BA, Brasil. (iD) https://orcid.org/0000-0002-0333-9515

Edgard Freitas Neto **

Universidade Federal da Bahia, Programa de Pós-Graduação em Relações Internacionais, Salvador-BA, Brasil.

(D) https://orcid.org/0000-0002-0566-1778

Nelson Cerqueira ***

Universidade Federal da Bahia, Programa de Pós-Graduação em Direito, Salvador-BA, Brasil. (iD) https://orcid.org/00oo-0002-4585-2317

Resumo: O presente trabalho visa analisar a configuração de uma legalidade extraordinária e de uma mutação inconstitucional decorrentes do surto de Covid-19 no Brasil em 2020 e da decretação por autoridades locais de medidas drásticas de restrição a direitos fundamentais no contexto do combate à referida pandemia. $\mathrm{O}$ estudo deste tema visa, através do método hipotético-dedutivo, analisar primeiramente as teorias sobre o estado de crise institucional e as mutações constitucionais para então contrastá-las com o caso concreto, isto é, a adoção do toque de recolher e do lockdown por autoridades locais na ausência de um estado de sítio que o justificasse. Conclui-se que as referidas medidas são inconstitucionais por desrespeitarem a vontade do legislador constituinte originário e que a tolerância do Judiciário frente a tais arbitrariedades produziu uma mutação inconstitucional por meio da qual se avaliza a suspensão de garantias constitucionais fora das hipóteses nas quais a própria Constituição o permite, tal como se o país estivesse vivendo uma legalidade extraordinária.
\end{abstract}

Palavras-chave: Coronavírus. Covid-19. Toque de recolher. Lockdown. Mutação inconstitucional. Estado de sítio.

* Mestrando em Direito na Universidade Federal da Bahia. Analista Técnico da Defensoria Pública do Estado da Bahia. E-mail: henriquebreda10@hotmail.com

** Mestre em Relações Internacionais pela Universidade Federal da Bahia. Gerente da Procuradoria Jurídica de Prerrogativas da Ordem dos Advogados do Brasil - Seção Bahia. E-mail: edgardcfn@gmail.com

**** Doutor em Literatura Comparada - Indiana University. Professor do Programa de Pós-Graduação da Faculdade de Direito da UFBA. E-mail: nelsoncerqueira1@gmail.com

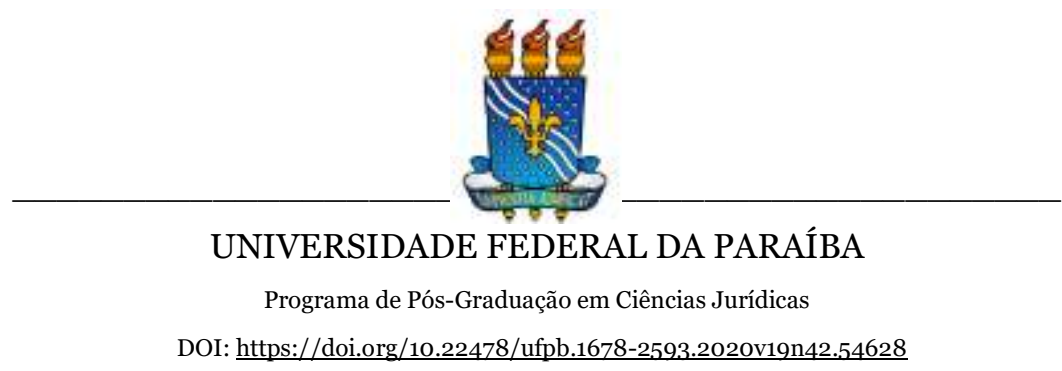




\title{
Toque De Recolher E Lockdown: A Mutação Inconstitucional Promovida Pelas Autoridades Locais No Combate À Covid-19 No Brasil
}

\author{
Henrique Breda Cavalcanti
}

Edgard Freitas Neto

Nelson Cerqueira

\section{INTRODUÇÃO}

No final do ano de 2019 o aparecimento de uma nova variedade de coronavírus denominado SARS-nCoV-2, causador de uma doença respiratória que passou a ser denominada Covid-19, foi identificado na cidade de Wuhan, na China. Os relatórios iniciais minimizaram seus efeitos e negaram a existência de indícios de transmissão entre seres humanos, até que a quarentena e lockdown impostos a Wuhan e cidades circunvizinhas no dia 23 de janeiro, afetando quase 60 milhões de pessoas, tornou-se evidente para o mundo o seu caráter altamente infeccioso.

Mesmo na ausência de um índice de letalidade em si mais elevado que o de outras doenças infecciosas, a velocidade de disseminação do novo coronavírus logo se mostrou um desafio para os Estados, uma vez que rapidamente conduzia a capacidade instalada dos serviços de saúde ao colapso, em especial os serviços de terapia intensiva ${ }^{1}$.

${ }^{1}$ O Ro (número básico de transmissão) do SARS-nCOV-2 é 3,5 (PÓVOAS, 2020). Isto exemplifica a progressão exponencial da doença, em que cada contaminado, coeteris paribus, pode contaminar em média 3,5 pessoas. Segundo as estimativas da 
No início do mês de fevereiro, entretanto, a pressão para o repatriamento de cidadãos brasileiros residentes na área sob lockdown revelou um dilema evidente: como trazer de volta para o território nacional pessoas expostas socialmente a um patógeno do qual pouco se sabe se não havia um marco legal que permitisse ao Estado impor uma quarentena a estas pessoas?

A rigor, nenhuma destas pessoas poderia ser obrigada a permanecer sob quarentena, como evidente consequência dos princípios constitucionais da legalidade e liberdade de locomoção, nos termos do art. $5^{\circ}$, II e XV da Constituição Federal (BRASIL, 1988).

Neste contexto, o Poder Executivo federal apresentou em 4 de fevereiro o Projeto de Lei 23/2020, tramitado em regime de urgência na Câmara dos Deputados, aprovado e sancionado dois dias depois como a Lei 13.979/2020 (BRASIL, 2020a), que determinou as medidas de enfrentamento da emergência de saúde apresentada pelo coronavírus, estabelecendo marcos regulatórios e definindo institutos como isolamento e quarentena.

Nesta senda, o presente artigo visa contrastar as teorias sobre o estado de crise institucional com a prática dos poderes constituídos no Brasil durante a pandemia do coronavírus em 2020, marcada pela imposição de certas medidas restritivas de direitos fundamentais sem a correspondente decretação de um estado de sítio.

O método utilizado é o hipotético-dedutivo, por meio do qual se formula uma hipótese para em seguida submetê-la a um teste de validação. A hipótese aqui investigada diz respeito à possível configuração de uma legalidade extraordinária e de uma concomitante mutação inconstitucional decorrentes da multiplicação de decretos de toques de recolher e lockdowns Brasil afora no contexto do combate à

Associação de Medicina Intensiva Brasileira, 20\% dos infectados precisam de hospitalização, e deste total $15 \%$ acabarão num leito de tratamento intensivo. No caso do Brasil, como o país já possuía um baixo índice de disponibilidade de vagas de terapia intensiva (tanto na rede privada como na púbica) a modelagem matemática indica a probabilidade de colapso na disponibilidade destes leitos à medida em que o patógeno avança em progressão exponencial (AMIB, 2020). 
pandemia, não obstante a ausência de um estado de sítio que legitimasse tais medidas.

\section{UM ESTADO DE CONFUSÃO INSTITUCIONAL}

A edição da lei, entretanto, não representou um aclaramento dos marcos regulatórios e institucionais sobre o combate à Covid-19. Conflitos e desinteligências de caráter político-partidário e institucional, que vinham crescendo em espiral desde o ano de 2019, atingiram seu ponto paroxístico com a pandemia.

Parte central das discussões girava em torno da constitucionalidade das medidas adotadas, com a União sustentando que medidas restritivas de direitos fundamentais, como o de ir e vir, só poderiam ser adotadas num estado de legalidade extraordinária, e de outro lado estados e municípios sustentando possuírem competência comum na matéria.

Idealmente, as regras, freios e contrapesos constitucionais e infraconstitucionais orientariam a ação dos poderes e entes federados. Ainda neste plano ideal, motivados pela ação em prol da res publica, os agentes e entes públicos deveriam cooperar. Afinal, a saúde pública é uma competência comum entre União, Estados e Municípios, nos termos do art. 23, II da Constituição (BRASIL, 1988). Trata-se de um consectário à ideia do equilíbrio federativo, decorrente da existência de ordens de autoridade (federal, estadual e municipal), a noção de que as mesmas deveriam agir harmonicamente, dentro de suas competências (MEDINA; MEDINA, 2020).

Com a edição da Medida Provisória 926/2020 (BRASIL, 2020b), que alterou trechos da Lei 13.979/2020, a União buscou ampliar as suas competências privativas nela previstas. Ao tempo da edição da MP, estados e municípios já estavam a editar normas e adotar políticas voltadas para o controle da doença que por vezes 
Toque De Recolher E Lockdown: A Mutação Inconstitucional Promovida Pelas...

conflitavam com aquelas defendidas pelo presidente Jair Bolsonaro, quem repetidamente se pronunciava contra medidas que relativizassem direitos e liberdades fundamentais do cidadão em nome do combate à pandemia.

Recorrendo à sua base de apoio popular, em especial o eleitorado evangélico, Bolsonaro passou a desafiar publicamente as propostas endossadas pela Organização Mundial de Saúde (OMS) e por governadores e prefeitos, como anotaram Py, Shiota e Possmozer (2020, p. 385):

Com efeito, trata-se de uma orientação que, em defesa do retorno imediato das atividades econômicas, aliando-se a setores religiosos, vem contrariando as iniciativas de governadores e prefeitos em prol do isolamento social horizontal com o fechamento das atividades não essenciais. Em menos de um mês, em plena crise sanitária, dois ministros da saúde que defendiam o isolamento social horizontal deixaram o cargo.

Ao redor do país surgiram os mais diversos atos administrativos que, em condições democráticas normais, seriam inconcebíveis: decretos municipais isolaram cidades de suas vizinhas, condicionando o ingresso em seus limites à existência de justificativa (ALAGOINHAS, 2020); decretos estaduais impuseram toques de recolher em múltiplas cidades (BAHIA, 2020). Até manifestações públicas contra os atos restritivos foram proibidas por decisões judiciais (MARANHÃO, 2020a) e se chegou a propor a criação de um tipo penal para fake news nas áreas da saúde e segurança pública (CÂMARA DOS DEPUTADOS, 2020). O combate à pandemia serviu como móvel e fundamento do aumento do controle estatal sobre os indivíduos de modo similar àquele descrito por Michel Foucault no Capítulo III do seu Vigiar e Punir como tendo ocorrido na Vincennes do século XVII, com

[...] a penetração do regulamento até nos mais finos detalhes da existência e por meio de uma hierarquia completa que realiza o funcionamento capilar do poder; não as máscaras que se colocam e se retiram, mas a determinação a cada um de seu "verdadeiro" nome, de seu "verdadeiro" lugar, de seu "verdadeiro" corpo e da "verdadeira" doença. A peste como forma real e, ao mesmo 
tempo, imaginária da desordem tem a disciplina como correlato médico e político (FOUCAULT, 2000, p. 163164).

A discussão, neste tocante, não se restringiu ao aspecto puro da biopolítica, de se tal ou qual política poderia ser adotada (ou a conveniência ou não de sua adoção), mas também, frequentemente sobre quem teria competência para adotá-las.

Os conflitos de competência sucederam-se não apenas em face da União, mas também entre os próprios estados e municípios: a imprensa noticiou em maio, por exemplo, que alguns municípios do estado de São Paulo questionaram judicialmente o timing de sua posição no plano de flexibilização imposto pelo governo estadual bandeirante (TOMAZELA, 2020); em junho, a Prefeitura de Caruaru questionou o endurecimento da quarentena imposto pelo governo estadual pernambucano no período das festas juninas (JC ONLINE, 2020).

Dois casos são paradigmáticos deste estado de confusão: Em 30 de abril de 2020, o juízo da Vara de Interesses Difusos e Coletivos de São Luís/MA, atendendo liminarmente a uma ação civil pública promovida pelo Parquet maranhense, impôs ao governo estadual e às prefeituras de São Luis, Raposa e Paço do Lumiar a adoção do lockdown naquelas cidades. Um trecho da decisão merece mais destaque:

No âmbito do Estado do Maranhão, por meio do Decreto Estadual $\mathrm{n}^{\mathrm{o}} 35.672$, de 19de março de 2020 , foi declarado estado de calamidade pública em todo o território estadual para fins de prevenção e enfrentamento ao vírus $\mathrm{H} 1 \mathrm{~N} 1$ e à COVID-19. Dentre outras medidas, o Decreto vedou o trânsito interestadual de ônibus no território do Estado do Maranhão. Ressalte-se, ainda, a edição do Decreto $\mathrm{n}^{0}$ 35.677, de 21 de março de 2020, que estabelece especificamente medidas de prevenção do contágio e de combate à propagação da transmissão da COVID-19, infecção humana causada pelo Coronavírus (SARS-CoV2), que determina a suspensão de uma série de atividades no território do Estado e impõe a adoção de medidas de isolamento social. As medidas de isolamento social e de proibição temporária de atividades que possibilitem aglomeração de pessoas, conforme autoridades sanitárias, órgãos e entidades representativas de técnicos da área da saúde, são as mais adequadas para o momento e têm a 
finalidade de retardar o crescimento da curva de disseminação do vírus. Ocorre, no entanto, que para o presente momento as medidas de distanciamento social estão se mostrando ineficazes para contenção da propagação do vírus causador da COVID-19, demandando do Poder Público a adoção de medidas mais intensas para evitar um colapso do sistema público de saúde, que, na Capital, já se evidencia, com a lotação máxima dos leitos de UTI destinados a pacientes com COVID-19 (...) No caso presente, é necessária adoção do bloqueio total, ainda que por curto período, pois essa é a única medida possível e eficaz no cenário para contenção da proliferação da doença e para possibilitar que o sistema de saúde público e privado se reorganize, a fim de que se consiga destinar tratamento adequado aos doentes (MARANHÃO, 2020b).

A referida decisão liminar consignou não apenas obrigações de fazer, mas também de não fazer, dentre outras, proibindo os Municípios no polo passivo de disciplinarem a questão de modo diverso (isto é, menos restrito) daquilo que se impunha ao Estado. Da consulta dos autos do processo eletrônico exsurge que não houve interposição de recurso em face da decisão, mas antes o seu acatamento ${ }^{2}$.

Já no Rio de Janeiro, em junho, situação análoga se desenrolou, mas com um resultado diferente. No bojo da Ação Civil Pública $n^{0}$ 0117233-15.2020.8.19.0001 (RIO DE JANEIRO, 2020a), promovida pela Defensoria Pública e Ministério Público fluminenses, o juízo da $7^{\text {a }}$ Vara da Fazenda Pública do Rio de Janeiro suspendeu decretos do Estado e do Município do Rio de Janeiro que flexibilizavam o lockdown até então imposto. O juízo entendeu, ali, que havia pouca clareza, da parte do governo estadual, sobre os critérios científicos utilizados na edição dos referidos decretos.

Esta decisão foi suspensa por decisão da presidência do Tribunal de Justiça estadual (RIO DE JANEIRO, 2020b), que entendeu ser da competência da chefia do Poder Executivo a definição de atividades essenciais, não cabendo ao Poder Judiciário imiscuir-se nesta escolha. Por sua vez, a tentativa da parte da DPE/RJ e do MP/RJ

2 Até 31/07/2020 o processo ainda não tinha sido sentenciado. 
de derrubar a suspensão através de reclamação ao Supremo Tribunal Federal (STF) não logrou êxito (BRASIL, 2020c).

Percebe-se, desta maneira, que ambas as decisões (do magistrado de piso no TJ/MA e do presidente do TJ/RJ) adotaram conclusões distintas para uma questão similar, vale dizer: a decisão de impor (ou não) o lockdown, bem como sua duração e intensidade é de competência exclusiva do Poder Executivo? Não, para o juízo maranhense. Sim, para o fluminense.

\section{A DECISÃo do STF SOBRE A COMPETÊNCIA PARA ADOTAR MEDIDAS RESTRITIVAS CONTRA A PANDEMIA}

O imbroglio em torno da competência, todavia, se iniciou quase que imediatamente após a edição da Lei 13.979/2020, e girou em torno da sua concorrência ou não entre os entes federados. O julgamento do STF que permitiu a governadores e prefeitos determinar medidas de restrição à circulação de pessoas em seus respectivos entes federativos foi proferido no âmbito da ADI 6.341 (BRASIL, 2020d), ajuizada pelo Partido Democrático Trabalhista (PDT) contra a Lei 13.979/2020.

$\mathrm{O}$ art. $3^{\circ}$ da mencionada lei estabelece um rol não-exaustivo de medidas que podem ser adotadas pelas autoridades, a exemplo do isolamento (isto é, a segregação de pessoas comprovadamente contaminadas) e da quarentena (isto é, a restrição de atividades e/ou segregação de pessoas com suspeita de contaminação) - tudo com o objetivo de evitar a contaminação ou propagação do coronavírus. $\mathrm{O} \S$ $7^{\circ}$ do mesmo dispositivo acrescenta que as ações em questão poderiam ser tomadas pelo Ministério da Saúde e/ou pelas autoridades de saúde locais, a depender da situação:

Art. $3^{\circ}$ Para enfrentamento da emergência de saúde pública de importância internacional decorrente do coronavírus, as autoridades poderão adotar, no âmbito de suas competências, dentre outras, as seguintes medidas: I - isolamento; 


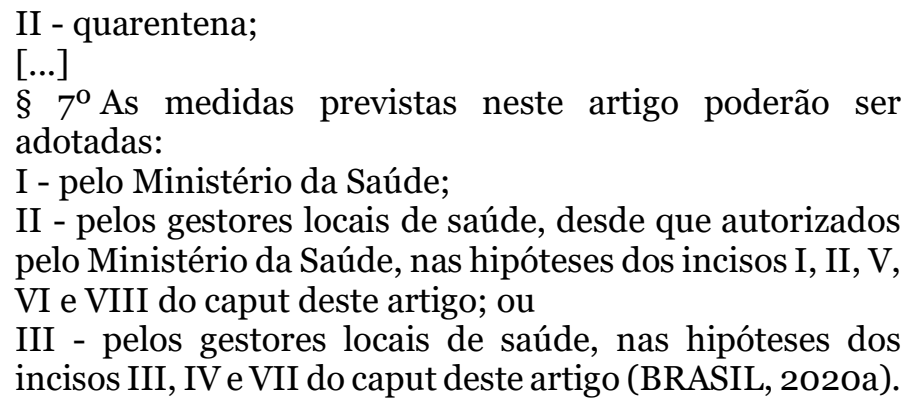

Por ser este um rol exemplificativo, a enumeração das medidas ali elencadas não exclui outras de que pudessem se valer as autoridades, como a suspensão de atividades econômicas. No entanto, os $\S \S 8^{\circ}$ e $9^{\circ}$ do art. $3^{\circ}$ preveem uma limitação nesse sentido: as ações a serem adotadas não poderiam interferir no funcionamento de serviços públicos e atividades essenciais, cabendo ao Presidente da República definir por decreto quais atividades se enquadrariam nessa classificação:

\footnotetext{
[...]

$\S 8^{\circ}$ As medidas previstas neste artigo, quando adotadas, deverão resguardar o exercício e o funcionamento de serviços públicos e atividades essenciais.

$\S 9^{\circ}$ O Presidente da República disporá, mediante decreto, sobre os serviços públicos e atividades essenciais a que se referem o § $8^{\circ}$ (BRASIL, 2020a).
}

O autor da ação direta de inconstitucionalidade se insurgiu especificamente contra o último parágrafo acima, alegando que a distribuição dos poderes de polícia instituída pela nova lei, ao centralizar no Presidente da República o poder de decidir, em última instância, quais serviços e atividades poderiam ou não ser interrompidos indistintamente em todo o país, iria de encontro ao art. 198, I da CF (BRASIL, 1988) que estabelece um regime de cooperação entre os entes federativos para a gestão do sistema de saúde e execução de ações de vigilância sanitária e epidemiológica.

O STF atendeu ao pedido e julgou a ação procedente por unanimidade de modo a facultar aos Estados e Municípios a adoção de medidas como o isolamento, a quarentena e a restrição excepcional e temporária de rodovias, portos ou aeroportos. $\mathrm{O}$ decreto presidencial 
sobre serviços e atividades essenciais, assim, não vincularia os gestores dos demais entes federativos no tocante à sua competência constitucional referente à saúde.

Esse entendimento da Suprema Corte se mostra correto; em uma Federação é coerente que as autoridades locais, mais próximas e melhor conhecedoras de suas próprias realidades, tenham a autonomia para tomar essas decisões.

É importante, contudo, ressaltar que a controvérsia levada ao Judiciário dizia respeito tão somente à seara do art. $3^{\circ}, \S 9^{\circ}$ e à competência para designar serviços e atividades como essenciais; sendo assim, a decisão do STF não pode ser considerada um salvoconduto para que as autoridades em questão adotem qualquer medida em relação aos cidadãos de maneira indiscriminada, como se abordará mais adiante nesse estudo.

\section{MUTAÇÕES CONSTITUCIONAIS E INCONSTITUCIONAIS}

Na lição de Anna Candida da Cunha Ferraz (2015), tem-se que as Constituições podem ser alteradas de duas maneiras: uma formal, instituída pela própria Constituição e revestida de forma, requisitos e limites expressos em seu texto; e outra informal, promovida por obra das forças políticas ou do costume social.

Para Caio Sperandeo Macedo (2019), não obstante as próprias Constituições estabeleçam critérios e processos formais para sua atualização por meio de emendas constitucionais, a doutrina atualmente reconhece a legitimidade de alterações informais de alteração das Constituições sem que haja alteração de seu texto, notadamente por meio da interpretação advinda dos órgãos competentes dos três Poderes, cada qual em sua legítima esfera de atuação. 
No Brasil, o processo formal de alteração constitucional se dá na forma do art. 60 da Carta Magna (BRASIL, 1988), através do qual é possível emendá-la mediante votação de três quintos dos membros de ambas as casas do Congresso Nacional. É importante novamente frisar que a emenda formal da Constituição sempre redunda numa alteração do seu texto. Nesse sentido, a Constituição Federal de 1988 é classificada pela doutrina como rígida, já que a alteração de suas disposições requer um procedimento mais rigoroso do que aquele destinado à alteração das leis infraconstitucionais (NETTO, 2019).

Já os processos informais de alteração da Constituição, por outro lado, independem de participação do parlamento e se dão de forma mais silenciosa, promovendo uma releitura dos dispositivos constitucionais de modo a alterar nunca a sua letra, mas antes o seu sentido ou interpretação (SAMPAIO, 2018).

Anna Candida da Cunha Ferraz (2015) esclarece que o gênero dos processos informais de alteração constitucional abriga ao mesmo tempo duas espécies diferentes de mutações: as que não violentam a Constituição, ou seja, as mutações constitucionais; e as que contrariam a Constituição e que, portanto, não devem subsistir, isto é, as mutações inconstitucionais.

\begin{abstract}
A expressão mutação constitucional é reservada somente para todo e qualquer processo que altere ou modifique o sentido, o significado e o alcance da Constituição sem contrariá-la; as modalidades de processos que introduzem alteração constitucional, contrariando a Constituição, ultrapassando os limites constitucionais fixados pelas normas, enfim, as alterações inconstitucionais são designadas por mutações inconstitucionais.

Assim, em síntese, a mutação constitucional altera o sentido, o significado e o alcance do texto constitucional sem violar-lhe a letra e o espírito [...]. Trata-se, pois, de mudança constitucional que não contraria a Constituição, ou seja, que, indireta ou implicitamente, é acolhida pela Lei Maior (FERRAZ, 2015, p. 9-10).
\end{abstract}

Arquétipos de mutações constitucionais no direito brasileiro incluem a ADPF 132 (BRASIL, 2011), na qual o STF permitiu a união estável homoafetiva no Brasil não obstante a ausência de previsão legal 
ou constitucional para tanto; e o HC 82.424 (BRASIL, 2003), mais conhecido como "caso Ellwanger", onde o conceito constitucional de racismo, a princípio restrito ao preconceito de raça ou de cor, foi expandido pela Suprema Corte de modo a abranger outras formas de discriminação, como a religiosa.

José Adércio Leite Sampaio (2018) relata que as referidas mutações têm sido o modo dominante de "atualização constitucional", por exemplo, nos Estados Unidos, tendo em vista a longevidade da Constituição daquele país e a obsolescência de seu texto original em relação à realidade contemporânea.

Ingo Wolfgang Sarlet (2019) e Anna Candida da Cunha Ferraz (2015) acrescentam que tais processos informais a princípio se justificam quando se trata de adaptar o texto constitucional a uma nova realidade social e não são de exclusividade do Poder Judiciário, podendo também em algumas ocasiões ser levados a cabo pelo Executivo e pelo Legislativo.

É justamente este, afinal, o caso em tela que serve de objeto ao presente trabalho: uma alteração informal da $\mathrm{CF} / 88$ pelas mãos dos poderes constituídos locais. Em algumas localidades isso se deu por ordem de governadores e prefeitos; em outras, por decisão da própria Justiça de primeira instância (SOTERO; SOARES, 2020). Tal alteração, contudo, ofende o espírito da Constituição e, portanto, deve ser enquadrada como mutação inconstitucional, conforme se demonstrará adiante.

\section{A INCONSTITUCIONALIDADE DAS MEDIDAS MAIS RÍGIDAS DE RESTRIÇÃO À CIRCULAÇÃO DE PESSOAS: TOQUE DE RECOLHER E LOCKDOWN}

No contexto das medidas de combate à pandemia do Covid-19 determinadas por autoridades locais no Brasil e no mundo, despontam 
como as mais invasivas o toque de recolher e o lockdown. O primeiro, menos intenso, diz respeito à restrição da circulação de pessoas nas vias públicas em determinado local e horário específicos; o segundo, mais radical, equivale à proibição total de que os cidadãos deixem suas moradias, sendo abertas exceções apenas para a compra de alimentos ou remédios, o trabalho em serviços essenciais, ou situações de emergência. Efetuando um levantamento quantitativo das medidas adotadas em diferentes países, Esteves et al. (2020, p. 151-152) constataram que

Na tentativa de conter a propagação do COVID-19, diversas nações restringiram reuniões (59\%), limitaram a quantidade ou a duração de saídas de casa por dia (20\%), além de adotarem outras espécies de restrições (27\%), tais como a imposição de toque de recolher (e.g. Geórgia, Macedônia do Norte), redução da capacidade dos transportes públicos (e.g. Etiópia, Portugal), etc.

Outrossim, a drástica medida do lockdown (proibição total de saída do domicílio) restou instituída em 47\% dos países estudados, sendo formalizada a previsão de prisão (41\%) e/ou multa (73\%) para o caso de descumprimento.

Deve-se ter em mente que a liberdade - de ir e vir, de se reunir, de trabalhar, etc - constitui, sob a Carta de 1988, o estado de normalidade constitucional. $\mathrm{O}$ art. $5^{\circ}$ da Constituição salvaguardou os direitos e garantias individuais condicionando sua restrição, individualmente, a condenação após o devido processo legal ou, coletivamente, à decretação de um estado de legalidade extraordinária.

A ideia de normalidade constitucional representa uma chave para a compreensão do dilema, pois é justamente a quebra da normalidade que justifica a excepcionalidade. Como observa Jorge Gouveia (2020, p. 2),

[...] no direito constitucional - através das soluções jurídico-materiais em que se traduz - o estado de exceção somente ganha real sentido nos sistemas em que seja possível discernir uma situação de normalidade caracterizada por um equilíbrio entre poder e liberdade de uma situação de exceção - marcada por um conjunto de transformações que permitem a hipertrofia daquele em desfavorecimento desta. 
Isto posto, observando-se as disposições da Constituição Federal, nota-se que a restrição à circulação de pessoas de forma indiscriminada (e não apenas em determinados lugares, ou para determinadas pessoas) só pode ser decretada na hipótese de estado de sítio, decretado pelo Presidente da República, conforme os arts. 136 e 139 (o estado de defesa, mais brando, admite restrições à locomoção física dos cidadãos somente no tocante à liberdade de reunião):

Art. 136. O Presidente da República pode, ouvidos o Conselho da República e o Conselho de Defesa Nacional, decretar estado de defesa para preservar ou prontamente restabelecer, em locais restritos e determinados, a ordem pública ou a paz social ameaçadas por grave e iminente instabilidade institucional ou atingidas por calamidades de grandes proporções na natureza.

$\S 1^{\circ} \mathrm{O}$ decreto que instituir o estado de defesa determinará o tempo de sua duração, especificará as áreas a serem abrangidas e indicará, nos termos e limites da lei, as medidas coercitivas a vigorarem, dentre as seguintes:

I - restrições aos direitos de:

a) reunião, ainda que exercida no seio das associações;

b) sigilo de correspondência;

c) sigilo de comunicação telegráfica e telefônica;

[...]

Art. 139. Na vigência do estado de sítio decretado com fundamento no art. 137, I, só poderão ser tomadas contra as pessoas as seguintes medidas:

I - obrigação de permanência em localidade determinada;

[...] (BRASIL, 1988, grifo nosso)

Não dispondo a Constituição de outros instrumentos que autorizem a restrição indiscriminada ao direito de ir e vir, isto é, direcionada à população em geral e não somente a alguma categoria de indivíduos (ex: os privados de liberdade em decorrência de sentença judicial), a conclusão inevitável é a de que a decretação do toque de recolher e lockdown pelas inúmeras autoridades estatais fora da hipótese dos estados de legalidade extraordinária previstos na Carta constitui uma inovação irregular em relação ao Texto Constitucional, posto que cria uma hipótese de restrição genérica e abstrata de direitos e garantias individuais sem previsão constitucional expressa. 
Romeu da Cunha Gomes (2020) assevera que a Constituição Federal de 1988 quis que o estado de crise obedecesse às normas previamente definidas para os estados de sítio e defesa; dessa forma, é teoricamente inviável admitir que os poderes constituídos possam valer-se das referidas circunstâncias extraordinárias para excepcionar a Constituição em termos e limites não estabelecidos por ela própria.

Considerando a inexistência de decreto de estado de sítio em solo pátrio - o que aqui não se sugere, nem tampouco se deseja - e a constatação de que apenas a eventual decretação deste regime excepcional admitiria uma restrição tão severa à liberdade dos cidadãos, algo inclusive vedado na hipótese de implemento de um eventual estado de defesa, a adoção da medida de lockdown revela-se flagrantemente inconstitucional (SOTERO; SOARES, 2020, p. 109).

Críticos dessa constatação acerca do toque de recolher e do lockdown poderiam apontar que não se trata propriamente de uma inovação irregular, mas antes de uma legítima mutação constitucional, na medida em que mutações constitucionais caracterizam-se justamente por alterar a Constituição. Poderiam, inclusive, invocar o precedente judicial da ADPF 132 (BRASIL, 2011), na qual o STF promoveu uma inovação - amplamente bem recebida pela doutrina e aceita como mutação constitucional - do texto do art. $226, \S 3^{\circ}$ da CF (BRASIL, 1988) para reconhecer outras hipóteses de família além daquela composta por "homem e mulher" (SARLET, 2019).

No entanto, como já visto acima, as mutações constitucionais não podem violar o espírito da Constituição, sob pena de transmutarse em mutações inconstitucionais. E no caso em testilha foi justamente isso que ocorreu com a inovação da Lei Fundamental pelas autoridades locais, na medida em que impuseram - quanto mais por simples decretos - restrições a direitos e garantias fundamentais típicos dos estados de legalidade extraordinária, mas sem as formalidades estabelecidas na Constituição.

Importa atentar, pois, novamente aos seguintes trechos dos dispositivos constitucionais anteriormente citados: o art. 136, § $1^{\mathrm{o}} \mathrm{diz}$ que poderão ser adotadas medidas coercitivas contra os cidadãos 
dentre as ali previstas; na mesma linha, o art. 139 assevera que só poderão ser tomados contra as pessoas os expedientes ali elencados (BRASIL, 1988).

O espírito da Constituição é assim, portanto, no sentido de cautelosamente limitar o exercício dos poderes emergenciais de que goza o Estado em momentos de crise, de modo a evitar que tais momentos sejam usados como pretexto para o surgimento de um regime autoritário ou a prática de abusos contra os cidadãos. Trata-se de uma preocupação que faz sentido, afinal de contas, é uma constituição filha de seu tempo, promulgada logo após a superação de um regime ditatorial, e num país com um longo histórico de autoritarismo político e de abuso dos estados de legalidade extraordinária (GOMES; MATOS, 2017).

Fosse a intenção do legislador constituinte que a administração pública, seja ela federal ou local, tivesse maior discricionariedade no tocante às medidas a serem tomadas no enfrentamento de crises; ou que tais medidas pudessem ser adotadas fora da excepcional hipótese do estado de sítio, teria ele se manifestado expressamente nesse sentido, mas não o fez. Sua preocupação foi manifestada justamente no sentido oposto, qual seja, o de privilegiar o resguardo dos direitos individuais do cidadão frente à ação estatal na contenção de ameaças à sociedade.

O controle do poder estatal, em vistas à sua contenção, é central na ciência política. Sustentando o conceito de freios e contrapesos, já em 1788 observou James Madison (2001, p. 121) que

[...] se os homens fossem anjos, nenhum governo seria necessário. Se anjos governassem os homens, controles internos e externos do governo seriam desnecessários. Ao estruturar um governo que deve ser administrado pelos homens sobre os homens, a grande dificuldade reside nisso: você primeiro deve permitir que o governo controle os governados; e em seguida obrigá-lo a controlar-se.

Não obstante, a história do poder, inclusive numa democracia, é a história do seu crescimento, crescimento este que se dá à custa das liberdades individuais, uma vez que, como observa Hans-Hermann 
Hoppe (2014), os integrantes do governo (em sentido lato, componentes de quaisquer dos três Poderes, em todos os seus níveis, inclusive os membros da burocracia) não possuem qualquer interesse em autolimitação ou autocontenção, mas, antes, incentivos para sua expansão. No caso das emergências, permanece válido o alerta de Giorgio Agamben (2004), para quem a tendência do estado de exceção é o de se tornar um paradigma de governo, na medida em que os detentores dos poderes excepcionais têm muitos incentivos para ampliar o conceito de emergência e prolongar sua duração.

Não se diga, ainda, que a eventualidade de uma pandemia de tais proporções não poderia ter sido prevista pelo constituinte originário, uma vez que o Brasil já fora atingido por grandes surtos de enfermidades contagiosas como a gripe espanhola (MUNIZ; FERIAS, 2019) e a meningite (SCHNEIDER; TAVARES; MUSSE, 2020), respectivamente na primeira e segunda metades do século passado; e que a ocorrência de calamidade natural é uma das hipóteses expressas que autorizam a decretação do estado de defesa e, na sequência, do estado de sítio, consoante os arts. 136 e 137, I da CF (BRASIL, 1988).

$\mathrm{O}$ objetor poderia persistir em sua posição alegando que mutações constitucionais podem ocorrer de modo a contrariar a vontade do constituinte originário, sendo isso, afinal de contas, o que aconteceu na ADPF 132. Na ocasião, o ministro Ricardo Lewandovski (BRASIL, 2011) expôs em seu voto que os deputados constituintes de 1988 definitivamente não desejavam que casais homossexuais pudessem ser reconhecidos como famílias aos olhos da lei.

Não obstante isso, Lewandowski alinhou-se à maioria de seus pares e votou a favor do reconhecimento das referidas uniões, entendendo que a vontade do legislador era um óbice que poderia ser superado pela importância dos princípios constitucionais envolvidos e que apontavam em sentido contrário.

Ocorre, no entanto, que ali a mutação estava amparada em uma evolução cultural da sociedade e se predispunha a ampliar um direito fundamental, e não a restringi-lo, como no caso dos toques de recolher 
e lockdowns. Sabe-se que normas restritivas de direitos não devem ser interpretadas de modo extensivo, e isso é relevante para se diferenciar o precedente da ADPF 132 da situação que ora se discute.

Nesse sentido, pontuam Débora Freitas e Marcelo Fernando Obregon (2019) que para a ocorrência de uma mutação é necessária uma mudança do paradigma social em que a Constituição foi criada, e acrescentam que o fenômeno não pode implicar retrocesso de direitos e garantias fundamentais, os quais incluem a livre locomoção no território nacional, nos termos do art. $5^{\circ}$, XV da CF (BRASIL, 1988).

Assim, se no caso da ADPF 132 havia uma mutação constitucional legítima e não violadora do espírito da Constituição, destinando-se a adequá-la a uma nova realidade sociocultural em relação à qual se encontrava obsoleta, no caso em testilha por sua vez o que se tem é uma mutação que não se explica por outro motivo senão a avaliação dos governadores e prefeitos de que, ante a resistência do governo federal em adotar medidas mais restritivas de circulação de pessoas, era necessário determiná-las em escala local, à revelia da União. Tratou-se, portanto, de uma burla da via constitucionalmente estabelecida do estado de sítio para a adoção de medidas desse porte.

Conclui-se, dessa forma, que a alteração informal da $\mathrm{CF} / 88$ promovida pelas autoridades locais do Brasil no contexto do combate à pandemia do Covid-19 configura uma mutação inconstitucional por violar o espírito da Carta Magna, que preza pela preservação das liberdades individuais do cidadão e estabelece parâmetros bem delineados a respeito das formas pelas quais se podem limitar essas liberdades. Na lição de Macedo (2019, p. 159),

Revela-se importante para garantir coesão e previsibilidade ao sistema jurídico referendar a corrente de pensamento majoritária, no sentido de se adotar parâmetros para a mutação constitucional ao respeitar os sentidos interpretativos possíveis do texto e os princípios fundamentais que lhe conferem identidade [...] (grifo nosso).

Não é possível, pois, a partir de previsões genéricas da Constituição, como o direito à saúde, extrair-se uma autorização para 
a adoção de medidas que atentem contra o regramento constitucional específico da matéria de restrições excepcionais aos direitos individuais do cidadão. O esmero do constituinte nesse ponto simplesmente não faria sentido caso se pudessem criar novas hipóteses de restrição desses direitos pelo arbítrio de quaisquer autoridades, desde o Prefeito até o Presidente da República, ainda que com justificativa em motivos nobres como o combate ao Covid-19.

Ingo Wolfgang Sarlet (2019) ressalta que as mutações inconstitucionais, muito embora inconstitucionais sejam, podem subsistir na prática devido a fatores como a inércia social e a complacência do Poder Judiciário para com as mesmas. Nesse contexto, é de se dizer que a atual crise do coronavírus vem produzindo uma aura que favorece a tolerância da sociedade e da comunidade jurídica em relação a patentes violações do texto constitucional.

É correta, assim, a observação de Romeu da Cunha Gomes (2020, p. 239): “[n]este quadro, a realidade fática disputa espaço com a normatividade da Constituição e vai encolhendo a sua abrangência sob a justificativa de que exceções são necessárias para responder às crises”. Para o referido autor, o contexto em análise acaba por criar um estado de exceção distinto daquele previsto constitucionalmente, materializado pela ação dos poderes constituídos, que reiteradamente vêm desrespeitando as garantias básicas que a Constituição visou assegurar ao cidadão mesmo em momentos emergenciais.

No entanto, como alertam Ana Paula da Silva Sotero e Ricardo Maurício Freire Soares (2020), a conjuntura da pandemia do Covid-19 não pode oportunizar o surgimento de uma "Constituição de emergência" mediante uma "jurisprudência de crise", embasando a suspensão ou restrição desproporcional de direitos individuais, assim como a normalização de abusos de poder por parte dos governantes, tal como se a Constituição Federal de 1988 tivesse sido, ela mesma, posta em quarentena. 


\section{CONCLUSÃO}

O advento da epidemia do coronavírus pôs em xeque a capacidade do ordenamento constitucional brasileiro de oferecer mecanismos constitucionais efetivos para o seu combate. Com efeito, viu-se que, diante do perigo que se assomava no horizonte, o sistema de freios e contrapesos destinado a preservar os direitos e garantias individuais falhou, permitindo que a emergência sanitária servisse como fundamento para um novo tipo de estado de exceção.

Trata-se, a bem da verdade, de um estado de exceção sui generis. Na história constitucional republicana brasileira a decretação de estados de exceção sempre foi uma prerrogativa do Executivo federal. Com razão - ou, mais normalmente, sem ela - o poder central invoca um inimigo - humano ou natural - cujo combate exige uma hipertrofia (supostamente temporária) deste mesmo poder.

Considera-se o estado atual como de exceção na medida em que os direitos individuais estão notoriamente restringidos por normas de caráter geral e abstrato. A diferença deste estado de exceção em relação aos seus precedentes reside no fato que seu exercício não está concentrado na União, mas sim difuso nos demais entes federativos, os quais podem emitir comandos mais restritivos do que aqueles emanados do ente federal, mas não menos.

À evidência, trata-se de uma mutação, pois, como visto, o tratamento constitucional sobre o estado de exceção visa precisamente à possibilidade do controle do seu exercício, como meio de preservar os direitos e liberdades que a Constituição consagra. Ao delegar a entes estaduais e municipais tais poderes - ou mesmo impor que o exerçam, quando inertes, como no caso do Maranhão - o Poder Judiciário chancelou uma mutação inconstitucional ao permitir (ou impor) o exercício de poderes emergenciais sem a decretação do ente federativo competente e ao descentralizar o seu exercício, trazendo insegurança jurídica. 
Esta insegurança jurídica decorre ainda do fato de que tais poderes emergenciais podem ser exercidos por meros decretos estaduais e municipais - e se revelam pouco transparentes e judicialmente controláveis quanto ao seu mérito.

Tal precedente é perigoso na medida em que a utilização dos poderes emergenciais para o combate a epidemias, ademais, propicia a normalização da exceção sob o rótulo de "nova normalidade", de forma que estas são muito mais frequentes e presentes do que a guerra que, historicamente, fornece a justificação clássica para extrapolação dos poderes públicos sobre os indivíduos.Ora, se o estado de exceção é um mal necessário, e recordando-se ao fim que toda Constituição deriva sua autoridade do consentimento dos governados, necessário se faz que estes vejam com ceticismo e receio a ampliação da concorrência na produção de tais males: a outorga de poderes emergenciais a uma infinidade de autoridades anônimas para restringir direitos individuais de modo genérico e abstrato, ainda que sob o pálio da melhor das intenções, não se coaduna com o espírito da Carta de 1988. A exceção não pode se tornar o novo normal institucional.

Data de Submissão: 18/08/2020

Data de Aprovação: 07/12/2020

Processo de Avaliação: double blind peer review

Editor Geral: Jailton Macena de Araújo

Editor de Área: Fernando Joaquim Ferreira Maia

Assistente Editorial: Andrea Neiva Coelho

\section{REFERÊNCIAS}

AGAMBEN, Giorgio. Estado de Exceção. São Paulo: Boitempo, 2004.

ALAGOINHAS. Decreto Municipal 5.245/202o, de 23 de março de 2020. Dispõe sobre medidas adicionais temporárias de 
prevenção e controle para enfrentamento do novo Coronavírus (COVID-19) no âmbito do município de Alagoinhas e dá outras providências. Disponível em:

https://leismunicipais.com.br/a/ba/a/alagoinhas/decreto/2020/524 /5245/decreto-n-5245-2020-dispoe-sobre-medidas-adicionaistemporarias-de-prevencao-e-controle-para-enfrentamento-do-novocoronavirus-covid-19-no-ambito-do-municipio-de-alagoinhas-ba-eda-outras-providencias. Acesso em: 29 jul. 2020.

ASSOCIAÇÃO DE MEDICINA INTENSIVA BRASILEIRA - AMIB. Comunicado da AMIB sobre o avanço do Covid-19 e a necessidade de leitos em UTIs no futuro. São Paulo. Disponível em:

http://www.somiti.org.br/arquivos/site/comunicacao/noticias/2020 /covid-19/comunicado-da-amib-sobre-o-avanco-do-covid-19-e-anecessidade-de-leitos-em-utis-no-futuro.pdf. Acesso em: 31 jul. 2020.

BAHIA. Decreto Estadual 19.926, de 10 de julho de 2020. Institui, nos Municípios indicados, a restrição de circulação noturna como medida de enfrentamento ao novo coronavírus, causador da COVID - 19, e dá outras providências. Disponível em: http://www.legislabahia.ba.gov.br/documentos/decreto-no-19826de-10-de-julho-de-2020. Acesso em: 29 jul. 2020.

\section{BRASIL. [Constituição (1988)]. Constituição da República}

Federativa do Brasil de 1988. Brasília, DF, 5 out. 1988.

Disponível em:

http://www.planalto.gov.br/ccivil_o3/constituicao/constituicao.htm . Acesso em: 19 mai. 2020.

BRASIL. Lei 13.979, de 6 de fevereiro de 2020. Dispõe sobre as medidas para enfrentamento da emergência de saúde pública de importância internacional decorrente do coronavírus responsável pelo surto de 2019. Brasília, DF, 6 fev. 2020a. Disponível em: http://www.planalto.gov.br/ccivil_03/_ato20192022/2020/lei/L13979.htm. Acesso em: 23 mai. 2020.

\section{BRASIL. Medida Provisória 926, de 20 de março de 2020.}

Altera a Lei $n^{0} 13.979$, de 6 de fevereiro de 2020, para dispor sobre procedimentos para aquisição de bens, serviços e insumos destinados ao enfrentamento da emergência de saúde pública de importância internacional decorrente do coronavírus. Brasília, DF, 20 mar. 202ob. Disponível em:

http://www.planalto.gov.br/ccivil_03/_ato20192022/2020/Mpv/mpv926.htm. Acesso em: 29 jul. 2020.

BRASIL. SUPREMO TRIBUNAL FEDERAL. Ação Direta de Inconstitucionalidade $\mathrm{n}^{\circ}$ 6.341/DF. Tribunal Pleno. Autor: Partido Democrático Trabalhista. Intimado: Presidente da República. 
Toque De Recolher E Lockdown: A Mutação Inconstitucional Promovida Pelas...

Relator: Min. Marco Aurélio Mello, DJe 06/05/2020. Brasília, DF, 15 de abril de 2020d. Disponível em:

http://portal.stf.jus.br/processos/detalhe.asp?incidente $=5880765$.

Acesso em: 22 mai. 2020.

\section{BRASIL. SUPREMO TRIBUNAL FEDERAL. Arguição de}

Descumprimento de Preceito Fundamental no 132/RJ.

Tribunal Pleno. Arguente: Governador do Estado do Rio de Janeiro. Arguidos: Tribunais de Justiça dos Estados e Assembleia Legislativa do Estado do Rio de Janeiro. Relator: Min. Ayres Britto, DJe 13/10/2011. Brasília, DF, 5 de maio de 2011. Disponível em: https://redir.stf.jus.br/paginadorpub/paginador.jsp?docTP=AC\&doc $\mathrm{ID}=628633$. Acesso em: 20 mai. 2020.

BRASIL. SUPREMO TRIBUNAL FEDERAL. Habeas Corpus no 82.424. Tribunal Pleno. Relator: Min. Maurício Corrêa, DJ 19/03/2004. Brasília, DF, 17 de setembro de 2003. Disponível em: http://redir.stf.jus.br/paginadorpub/paginador.jsp?docTP=AC\&docI $\mathrm{D}=79052$. Acesso em: 20 mai. 2020.

BRASIL. SUPREMO TRIBUNAL FEDERAL. Medida Cautelar na Reclamação no 41.791/RJ. Presidência do Supremo Tribunal Federal. Autores: Ministério Público do Estado do Ri de Janeiro e Defensoria Pública do Estado do Rio de Janeiro. Réu: Presidente do Tribunal de Justiça do Estado do Rio de Janeiro. Relator: Min. Dias Toffoli, DJe 15/o7/2020. Brasília, DF, 13 de julho de 2020c. Disponível em http://stf.jus.br/portal/diarioJustica/listarDiarioJustica.asp?tipoPes quisaDJ=AP\&classe $=$ Rcl\&numero=41791. Acesso em: 30 jul. 2020.

\section{CÂMARA DOS DEPUTADOS. Projeto pune com prisão quem} divulgar informação falsa sobre pandemia. Portal da Câmara dos Deputados, 26 mar. 2020. Disponível em https://www.camara.leg.br/noticias/648085-projeto-pune-comprisao-quem-divulgar-informacao-falsa-sobre-pandemia/. Acesso em: 15 jul. 2020.

ESTEVES, Diogo; ALVES, Cleber Francisco; SILVA, Franklyn Roger Alves. AZEVEDO, Julio Camargo. Acesso à Justiça em Tempos de Pandemia: o impacto global do COVID-19 nas instituições políticojurídicas. Revista Confluências, Niterói, v. 22, n. 2, ago./dez. 2020, p. 147-170. Disponível em:

https://periodicos.uff.br/confluencias/article/view/43014/25369. Acesso em: 22 set. 2020.

FERRAZ, Anna Candida da Cunha. Processos Informais de Mudança da Constituição: Mutações Constitucionais e Mutações Inconstitucionais. 2. ed. Osasco: EDIFIEO, 2015.

FOUCAULT, Michel. Vigiar e Punir. 22. ed. Petrópolis: Vozes, 
2000.

FREITAS, Débora Pauli; OBREGON, Marcelo Fernando Quiroga. A mutação constitucional in casu: breve análise da mutação constitucional do art. 124 da Constituição mexicana. Revista Derecho y Cambio Social, Peru, n. 55, p. 294-306, jan.-mar. 2019. Disponível em: https://lnx.derechoycambiosocial.com/ojs-3.1.14/index.php/derechoycambiosocial/article/view/45/32. Acesso em: 23 mai. 2020.

GOMES, Ana Suelen Tossige; MATOS, Andityas Soares de Moura Costa. O estado de exceção no Brasil republicano. Revista Direito e Práxis, Rio de Janeiro, v. 8, n. 3, p. 1760-1787, set. 2017. Disponível em: https://www.scielo.br/pdf/rdp/v8n3/2179-8966-rdp-8-31760.pdf. Acesso em: 21 mai. 2020.

GOMES, Romeu da Cunha. A Constituição em Tempos de Crises e a Pandemia da COVID-19. In: BAHIA, Saulo José Casali. MARTINS, Carlos Eduardo Behrmann Rátis (Coords). Direitos e Deveres Fundamentais em Tempos de Coronavirus. São Paulo: IASP, 2020, v. 1, p. 233-242.

GOUVEIA, Jorge Bacelar. Estado de Exceção no Direito Constitucional - Uma perspectiva do constitucionalismo democrático. Lisboa: Almedina, 2020.

JEFFERSON, Thomas. Declaration of Independence of the United States. In: BEEMAN, Richard (Org.). The Penguin Guide to the United States Constitution. Nova York: Penguin, 2011.

HOPPE, Hans-Hermann. Democracia: o Deus que Falhou. São Paulo: Instituto Mises Brasil, 2014.

JC ONLINE. Prefeitura de Caruaru contesta decisão do governo do Estado de endurecer quarentena em pleno São João. São Paulo, 23 jun. 2020. Disponível em: https://jc.ne10.uol.com.br/pernambuco/2020/o6/5613756prefeitura-de-caruaru-contesta-decisao-do-governo-do-estado-deendurecer-quarentena-em-pleno-sao-joao.html. Acesso em: 29 jul. 2020.

MACEDO, Caio Sperandeo. Mutação constitucional e a transformação da realidade e da percepção do direito na sociedade da informação. Revista Jurídica Direito \& Paz, Lorena, n. 41, p. 145161, jul.-dez. 2019. Disponível em:

http://revista.unisal.br/lo/index.php/direitoepaz/article/view/1096/ 498. Acesso em: 23 mai 2020.

MADISON, James; HAMILTON, Alexander; JAY, John. Selected Federalist Papers. Nova Iorque: Dover Publications, 2001 
MARANHÃO. TRIBUNAL DO JUSTIÇA DO ESTADO DO MARANHÃO. Cautelar Inominada no $0811462-$

64.2020.8.10.0001. Vara de Interesses Difusos e Coletivos de São Luís - MA. Juiz Douglas de Melo Martins. São Luís, MA, 27 mar. 2020. Disponível em: https://www.conjur.com.br/dl/justica-barracarreatas-isolamento.pdf. Acesso em: 22 set. 2020a.

MARANHÃ̃. TRIBUNAL DO JUSTIÇA DO ESTADO DO MARANHÃO. Ação Civil Pública no o813507-

41.2020.8.10.0001. Vara de Interesses Difusos e Coletivos de São Luís - MA. Juiz Douglas de Melo Martins, DJe 05/05/2020. São Luís, MA, 30 abr. $2020 b$.

MEDINA, Janaina de Castro Marchi; MEDINA, José Miguel Garcia. Saúde e contornos do federalismo brasileiro: bases constitucionais para a solução de conflitos relacionados à pandemia (Covid-19, coronavírus): breves considerações. Revista dos Tribunais, São Paulo, v. 109, n. 1017, jul. 2020.

MIGALHAS. Justiça proíbe carreata pelo fim do isolamento em Ribeirão Preto/SP. 28 de março de 2020. Disponível em https://www.migalhas.com.br/quentes/322995/justica-proibecarreata-pelo-fim-do-isolamento-em-ribeirao-preto-sp. Acesso em: 15 jul. 2020.

MUNIZ, Érico Silva Alves; FERIAS, Silviane de Carvalho. A influenza entre nós: a interiorização da gripe espanhola na Amazônia e a chegada da doença a Bragança (PA) (1918). Revista Fronteiras \& Debates, Macapá, v. 6, n. 2, p. 67-84, jul.-dez. 2019. Disponível em: https://periodicos.unifap.br/index.php/fronteiras/article/view/5375 /pdf. Acesso em: 19 mai 2020.

NETTO, Nelson Rodrigues. Mutações constitucionais: alteração da Constituição pela sua interpretação e a influência da sociedade em rede. Revista Jurídica Luso-Brasileira, Lisboa, v. 5, n. 1, p. 14571494, 2019. Disponível em:

http://www.cidp.pt/revistas/rjlb/2019/3/2019_03_1457_1494.pdf. Acesso em: 22 mai 2020.

PÓVOAS, Cid Edson Mendonça. Covid-19: Gráficos e dados em R. Ilhéus, 3 jul. 2020. Disponível em: https://cid.ezsites.com.br/. Acesso em: 29 jul. 2020.

PY, Fábio; SHIOTA, Ricardo; POSSMOZER, Michelli. Evangélicos e governo Bolsonaro: aliança nos tempos de Covid-19. Revista Confluências, Niterói, v. 22, n. 2, ago./dez. 2020, p. 384-406. Disponível em: https://periodicos.uff.br/confluencias/article/view/43024/25360. Acesso em: 22 set. 2020. 
RIO DE JANEIRO. TRIBUNAL DE JUSTIÇA DO ESTADO DO RIO DE JANEIRO. Ação Civil Pública no o117233-

15.2020.8.19.0001. $7^{\text {a }}$ Vara da Fazenda Pública da Comarca da Capital. Juiz Bruno da Rós Bodart. Rio de Janeiro, RJ, 8 de junho de 2020a.

RIO DE JANEIRO. TRIBUNAL DE JUSTIÇA DO ESTADO DO RIO DE JANEIRO. Suspensão de Execução no oo36361-

16.2020.8.19.0000. Relator: Des. Claudio de Melo Tavares. Rio de Janeiro, RJ, 9 de junho de 2020b.

SAMPAIO, José Adércio Leite. Federalismo e mutações constitucionais. Revista do Direito, Santa Cruz do Sul, v. 1, n. 54, p. 20-39, jun. 2018. Disponível em:

https://online.unisc.br/seer/index.php/direito/article/view/9980. Acesso em: 19 mai 2020.

SCHNEIDER, Catarina Menezes; TAVARES, Michele; MUSSE, Christina. O retrato da epidemia de meningite em 1971 e 1974 nos jornais O Globo e Folha de S. Paulo. Revista Eletrônica de Comunicação Informação \& Inovação em Saúde, Rio de Janeiro, v. 9, n. 4, out./dez. 2015. Disponível em: https://www.reciis.icict.fiocruz.br/index.php/reciis/article/view/995 /1995. Acesso em: 22 set. 2020.

SOTERO, Ana Paula da Silva; SOARES, Ricardo Maurício Freire Soares. Constituição e Restrição a Direitos Fundamentais em Tempos de Pandemia de COVID-19: um Breve Estudo do lockdown no Estado do Maranhão. In: BAHIA, Saulo José Casali. MARTINS, Carlos Eduardo Behrmann Rátis (Coords). Direitos e Deveres Fundamentais em Tempos de Coronavirus. São Paulo: IASP, 2020, v. 2, p. 91-110.

TOMAZELA, José Maria. Prefeitos do interior e do litoral contestam plano de reabertura do governo de SP. Estadão, São Paulo, 28 mai. 2020. Disponível em: https://saopaulo.estadao.com.br/noticias/geral,prefeitos-do-interior-e-dolitoral-contestam-plano-de-reabertura-do-governo-desp,70003317379. Acesso em: 29 jul. 2020. 
Toque De Recolher E Lockdown: A Mutação Inconstitucional Promovida Pelas...

\title{
Curfew And Lockdown: The Unconstitutional Mutation Promoted By Local Authorities While Fighting Covid-19 In Brazil
}

\author{
Henrique Breda Cavalcanti
}

Edgard Freitas Neto

Nelson Cerqueira

\begin{abstract}
The present article aims to verify the configuration of an extraordinary legality and an unconstitutional mutation in Brazil, both caused by the Covid-19 pandemic in that country in 2020 and by the imposition by local authorities of drastic measures against fundamental rights in the context of fighting the mentioned pandemic. The study of this subject aims, through the hypothetical-deductive method, first to analyze the theories on the state of institutional crises and the constitutional mutations and then proceed to contrast them with the concrete case, that is, the adoption of curfew and lockdown measures by local authorities in the absence of a state of siege that could justify it. We conclude that the mentioned measures are unconstitutional since they disregard the Framers' intentions on the matter and that judicial tolerance with such arbitrariness has produced an unconstitutional mutation by means of which it is allowed to suspend constitutional rights outside of the hypotheses in which the Constitution itself allows it, as if the country was living an extraordinary legality.
\end{abstract}

Keywords: Coronavirus. Covid-19. Curfew. Lockdown. Unconstitutional mutation. State of siege.

DOI: https://doi.org/10.22478/ufpb.1678-2593.2020v19n42.54628

Conteúdo sob licença Creative Commons: Attribuition-NonCommercial-NoDerivative 4.o International (CC BY-NC-ND 4.0) 